\title{
Health-related quality of life and well-being health state values among Dutch oldest old
}

This article was published in the following Dove Press journal:

Patient Preference and Adherence

\author{
Riaan Botes' \\ Karin M Vermeulen' \\ Anthonie M Gerber ${ }^{2}$ \\ Adelita $\vee$ Ranchor ${ }^{3}$ \\ Erik Buskens' \\ 'Department of Epidemiology, University \\ Medical Center Groningen, University of \\ Groningen, Groningen, 9700 RB, The \\ Netherlands; ${ }^{2}$ Department of Basic \\ Medical Sciences, Faculty of Health \\ Sciences, University of the Free State, \\ Bloemfontein, 9300, South Africa; \\ ${ }^{3}$ Department of Health Psychology, \\ University Medical Center Groningen, \\ University of Groningen, Groningen, \\ 9700 AD, The Netherlands
}

Background: Valuing hypothetical health states is a demanding personal process, since it involves the psychological evaluation of hypothetical health states. It seems plausible that elderly individuals will value hypothetical health states differently than the general population. It is, however, important to understand the psychological division that oldest old subgroups construct between acceptable and unacceptable health states. This information can produce important evidence regarding well-being and disability conceptualization.

Objective: To investigate how Dutch oldest old, conceptualize health-related quality of life health states when compared to well-being health states. In addition, we aim to compare subgroups, based on dependency classification.

Methods: Ninety-nine elderly living in the Groningen, Hoogeveen and Veendam areas of the Netherlands participated in the study. Respondents were classified into three groups based on dependency levels. The respondents were asked to value hypothetical health states, a generic preference-based HRQoL and a well-being instrument, using a visual analog scale. Results: All three groups ranked the same health states, from both questionnaires, below the average across the health states. The health-related quality of life health states was consistently ranked lower than the current well-being health states.

Conclusions: Health state valuations performed by the oldest old indicate that conceptually, respondents view below average health-related and well-being health states as undesirable. The results indicated that the oldest old do view deficits in health-related health states as more important than deficits in well-being health states. Since the oldest old performed the valuations, focused interventions to improve below average health-related outcomes might be the most cost-effective way to increase oldest old well-being outcomes.

Keywords: oldest old, valuation, health states, health-related quality of life (HRQoL), wellbeing

\section{Introduction}

Different populations may have quite different opinions on the impact of health states, ie, show considerable variation in the valuation of health states. ${ }^{1}$ This notion has resulted in continuous debates on the validity of general societal valuation methods reflecting the "average" citizens' health state preferences, and whether the valuation process should rather be performed by the specific or affected group of the population instead. $^{2}$ Typically health state valuation exercises are utilized to investigate the values patients, the general population or specific groups attach to hypothetical health-related quality of life (HRQoL) or well-being health states. However, this study was done concerning the descriptive and nuanced experience of aging as described by various elderly contexts and perspectives on health values. ${ }^{3}$
Correspondence: Riaan Botes Department of Epidemiology, University Medical Center Groningen, University of Groningen, PO Box 30.00I, Groningen

9700 RB, The Netherlands

Tel +312779359735I

Email BotesR@umcg.nl 
Considering the abovementioned, it seems plausible that certain subgroups of elderly will value hypothetical health states differently than the general population. Interestingly, demographic variables such as age, sex and educational level only partially explain the variance in health state valuations observed. ${ }^{4}$ Additional factors such as level of disability, the functional outcome/domain affected, availability of resources and type of disease may all impact on the valuation process. ${ }^{5}$

Moreover, valuing hypothetical health states is an arduous personal process, since it involves a psychological evaluation of hypothetical health states. ${ }^{6}$ In the case of the oldest old, typically 80 years and above, age may be a unique modifier of health state valuation. It has been demonstrated that $80+$ individuals may be suffering from several chronic diseases, possibly significantly impairing activities of daily living, as well as increasing cognitive impairment. This subgroup might very well value health states differently from their younger elderly counterparts. ${ }^{7,8}$ The current study was however concerned with investigating health state valuations, within oldest old subgroups, based on dependency classification. Dependency classification typically referring to living independently, living dependently with moderate care or living in a nursing home requiring consistent care. The oldest old group, almost without exception, suffers from several ailments and suboptimal health. ${ }^{9,10}$ The question is whether indeed the perceived quality of life falls below the average for the oldest old subgroups. Possibly health states can be identified that are valued as worse, suggesting that these health states contribute to poorer HRQoL and wellbeing. Implicitly this suggests that if society can define disability and well-being in terms of what the oldest old deem as acceptable and unacceptable states of health, treatment guidelines will have to be adapted to accommodate their wishes. Acceptable and unacceptable health states might be different between subgroups and between HRQoL and wellbeing health states, which can further explain the value the oldest old attach to states of health and disability.

To measure HRQoL and well-being, several instruments have been developed. The EQ-5D is a well-known and widely utilized instrument that mainly focuses on valuing HRQoL. ${ }^{11,12}$

Another approach was taken in developing a relatively new instrument, focussing on a well-being perspective. ${ }^{13}$ Typically, these newer instruments are developed to expand HRQoL by including and broadening the health content to produce well-being measures. Thus, the concept of health will include and in fact become a more comprehensive concept of capabilities and functionings. Instruments like the ICECAP-O and ASCOT emerged. ${ }^{14}$

The ICECAP-O is an instrument grounded in the theory of the capability approach.

Sen's capability approach describes health as being composed of both capabilities and functionings. ${ }^{15}$ The notion of capabilities and functionings are important, since capabilities refer to the possibilities one can achieve or aspire to achieve. Functionings refer to actual achievements and accomplishments. ${ }^{16}$ While actual achievements are essential to realize health and well-being goals, "feeling" capable to achieve and strife for better health might be the first step to actual achievement of the HRQoL and wellbeing goals. Implicitly this suggests that capabilities have a strong psychological component of how people perceive their future quality of life and well-being. ${ }^{6}$ The valuation of health states is therefore related to acceptable and unacceptable capabilities of the oldest old age groups. Being able to project yourself into the future with a positive view on your health and well-being might be important to adapt to a disease-affected life.

Deficits in capability and functionings could have negative repercussions on achieving appropriate health care goals. ${ }^{17}$ As with HRQoL, specific diseases will also impact on the capability and functionings impeding individual and societal health care goals. ${ }^{18,19}$ Evidently maintaining personal and health resources is important to achieve relevant health and non-health capabilities and functionings. ${ }^{20}$ It is therefore important to understand how oldest old dependency subgroups value HRQoL and well-being health states. Understanding the psychological division the oldest old construct between acceptable and unacceptable health states can yield valuable information regarding well-being, disability and mortality profiles. ${ }^{21}$ Our hypothesis is that the valuations performed by the subgroups of oldest old will identify HRQoL and well-being health states that are subjectively valued as acceptable while other health states are valued as unacceptable.

\section{Objective}

To investigate how Dutch oldest old, conceptualize HRQoL health states when compared to well-being health states. In addition, we aim to compare subgroups based on dependency classification. 


\section{Methods}

\section{Participants and study design}

Elderly individuals living in the Northern area of the Netherlands were recruited (Groningen, Veendam, Hoogeveen). The only inclusion criteria specified was that respondents had to be aged 65 years an older. They could be living independently and looking after themselves, living dependently with moderate care from family or a health professional or living in a nursing home requiring comprehensive care from a health professional. Dependency was established by asking the respondents to indicate with which subgroup they identified most. The recruitment process involved a) contacting the elderly via telephone, b) asking whether they would be willing to participate in the study c) checking whether the individual fits the inclusion criteria d) making an appointment with the individuals that fitted the inclusion criteria and e) meeting the elderly participants, at their place or residence, to conduct the interview.

Structured interviews were conducted with a generic preference-based HRQoL instrument, the EQ5D+C and a well-being instrument the Currently Achieved Functioning questionnaire (CAF). The respondents were asked to value hypothetical health states using a visual analog scale (VAS). Ten hypothetical health states per instrument were presented.

The average value was calculated, across the ten health states, for each oldest old subgroup to determine which health states were below the average and possibly deemed undesirable by the elderly subgroups. All respondents completed and signed informed consent forms to participate in the study. Ethical approval was obtained from the UMCG ethical committee (Metc 2011/041), regarding the procedures and methods used in this study (reference number M11.098466).

\section{Measures}

\section{$\mathrm{EQ}-5 \mathrm{D}+\mathrm{C}$}

The EQ- $5 \mathrm{D}+\mathrm{C}$ is a descriptive system whereas for the EQ5D-3L utility, values are available. The instrument was developed by the EuroQol group and mainly focuses on health-related quality of life (HRQoL).The EQ-5D-3L can be extended by adding on a so-called bolt-on domain. The domains included in the EQ-5D $+\mathrm{C}$ are mobility, self-care, usual activities, pain/discomfort, anxiety/depression and cognition (cognition being the bolt on here) (http://www. euroqol.org/ $/{ }^{11,22,23}$ For each domain three possible answer categories exist: 1 . no problem, 2. moderate problems, 3. extreme problems.

\section{Currently achieved functionings questionnaire (CAF)}

The CAF instrument is theoretically embedded in the capability approach. ${ }^{24}$ The questionnaire used to assess the feasibility and appropriateness of the capability approach was developed and send out prior to the formal launch of the ICECAP-O questionnaire. We, therefore, relied on the attributes identified by Grewal et $\mathrm{a}^{25}$ to develop the CAF questionnaire. The attributes, identified in the above mentioned paper, were utilized to construct a questionnaire related to the concept of capabilities/functionings. CAF is a preference-based instrument, designed specifically for the elderly, with a broader perspective on HRQoL and includes domains like attachment (feelings of love and affection), enjoyment (activities providing joy or pleasure), security (feeling secure when considering health and finances), role (having a purpose) and control (making one's own decisions). ${ }^{26}$ Pilot studies have been performed in the Netherlands and in South Africa to test the feasibility and the validity of the CAF questionnaire. ${ }^{27}$ From the results of the pilot studies, individuals from different subgroups and even different parts of the world indicated that they are able to value, describe and complete the $\mathrm{CAF}$ questionnaire.

\section{Health state valuation}

A VAS was also utilized for the valuation exercise. The VAS is a vertical line, ranging from zero to 100 . Zero on the scale represented the worst imaginable health state while hundred represented the best imaginable health state. Respondents in this study were instructed to value 10 hypothetical health states from the CAF questionnaire, using a VAS. The health states chosen were; 11111, 11122, 11245, 11312, 12335, 21114, 33333, 33544, 44433, 55555. One (1) constitute the ability to obtain "all" in the attribute, 2 constitute the ability to obtain "a lot" in the attribute, 3 constitute obtaining "some" of the attribute, 4 constitute obtaining "a little" and 5 constitute obtaining "none" of the attribute. Health state 12,335 will therefore constitute; all attachment, a lot of enjoyment, some security, some purpose in life and no sense of control.

Respondents were also instructed to value 10 hypothetical EQ-5D $+\mathrm{C}$ health states using a VAS. The health states chosen were 111111, 112112, 212111, 111221, 212121, 133113, 212321, 333211, 323331, and 333333. One (1) constitutes full health in attribute, 2 constitutes "some" deficits in attribute and 3 constitutes extreme problems in attribute. Health state 212321 will therefore 
constitute; some problems in mobility, no problems in selfcare, some problems in activities of daily living, extreme problems with pain experience, some problems with anxiety and no problems with cognition. The health states, from both questionnaires, were selected to reflect a representative spectrum of health states from better to worse.

\section{Statistical analysis and calculations}

Mean VAS scores for the 10 EQ-5D+C and 10 CAF hypothetical health states were calculated for the three subgroups, ie, independent, semi-dependent and dependent. The average converted VAS scores for each health state were calculated. The scores of the health states for each subgroup were then compared and reported. The following formula was used to convert the VAS scores. $^{28}$

\section{VASvalue $=$}

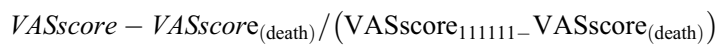

Typically, the converted VAS scores can be utilized to calculate quality-adjusted life years (QALY) for a specific group, sample or population. ${ }^{29}$ In general terms, the QALY is expressed as the value respondents assign to a specific health state, multiplied by the hypothetical length of time spent in the specific state. ${ }^{29}$ The QALY, therefore, provides a single index number that provides the opportunity to compare health outcomes or health care interventions. Our study however focussed on valuations performed by the oldest old to understand the conceptual differences between HRQoL health states when compared to well-being health states. We focused on the descriptive statistics, converted VAS values and average converted VAS values. Best to worse ranking exercises were applied to the health states, since the objective of this study was to investigate the subjective values that oldest old subgroups place on HRQoL and well-being health states. We utilized the converted VAS values to identify which health states are below the average values of the converted VAS scores. Ranked health states below the average values of the converted VAS scores were also compared between the EQ$5 \mathrm{D}+\mathrm{C}$ and the CAF questionnaire.

\section{Results}

The total sample of the study composed of 99 respondents, 29 living independently, 30 living semi-dependently with moderate care and 40 living in a nursing home requiring consistent care. Table 1 indicates the socio-demographic variables for the three groups. Noteworthy observations are that the majority of the respondents were female, with an average age of 80 years and above for all three groups. Only the dependent group reported that they have more than two people in the household. The disease profiles for all three groups appear to be similar, with the exception of the dependent elderly, reporting higher prevalence of heart disease and stroke but with fewer psychological disorders.

\section{Health-related quality of life valuations}

The dependent, semi-dependent and independent elderly groups awarded state 111111 with the maximum score of 1.00. The dependent, semi-dependent and independent groups all ranked the following health states below the average across the health states: 133113; 212321; 333211; $323331 ; 333333$.

Upon investigation of the EQ-5D+C subgroup valuations (Table 2), it became clear that the dependent elderly group-valued all the health states the higher, with the exception of health state 212321 .

The results from the EQ-5D+C valuations exercise, indicates that the respondents also valued better health states closer to one and worse health states closer to zero.

\section{Well-being valuations}

The CAF valuations indicate that the respondents valued better health states closer to one and worse health states closer to zero (Table 3). The dependent, semi-dependent and independent elderly awarded health state 11111 a value of 1.00. In the dependent, semi-dependent and independent groups, a similar trend is evident. All the groups ranked the same health states, 11245; 12335; 33544; 44433 and 55555, below the average, across all the health states. Additionally, the dependent group-valued health state 33333 below the average across the health states. The dependent groupvalued 12335; 33544; 44433 and 55555 health states the highest, compared to the other two groups.

\section{Health-related vs well-being valuations}

Upon comparison of the EQ-5D+C and CAF health states below the subgroup average, it becomes apparent that the EQ-5D+C health states were consistently ranked lower than the ranked CAF health states. Across the subgroups, the worst health state in the CAF valuations, 55555, is valued considerably higher than the worst EQ-5D+C, 333333, health state. However, in both the EQ-5D+C and CAF, all three subgroups valued the best health state with the highest value possible: 1.00 . 
Table I Socio-demographic and disease variables

\begin{tabular}{|c|c|c|c|c|c|}
\hline & $\begin{array}{l}\text { Dependent } \\
n=40\end{array}$ & $\begin{array}{l}\text { Semi- } \\
\text { dependent } \\
n=30\end{array}$ & $\begin{array}{l}\text { Independent } \\
\mathrm{n}=\mathbf{2 9}\end{array}$ & $P$-values & Significance \\
\hline Age mean [range] & 87 [8I-93] & $83[75-89]$ & 80 [69-87] & ns & \\
\hline Female, n (\%) & $33(83)$ & $21(70)$ & $22(76)$ & ns & \\
\hline \multicolumn{6}{|l|}{ Education } \\
\hline Primary, n (\%) & $13(33)$ & $12(40)$ & $10(34)$ & ns & \\
\hline Secondary & $9(23)$ & $8(27)$ & $10(34)$ & ns & \\
\hline Vocational training & $13(33)$ & $8(27)$ & $5(17)$ & ns & \\
\hline $\begin{array}{l}\text { Higher education/ } \\
\text { University }\end{array}$ & $5(13)$ & $2(7)$ & $3(10)$ & ns & \\
\hline Other & & & I (3) & ns & \\
\hline Spiritual interest Yes & $21(53)$ & $16(53)$ & $13(45)$ & ns & \\
\hline \multicolumn{6}{|l|}{$\begin{array}{l}\text { Number of people in } \\
\text { household, } N(\%)\end{array}$} \\
\hline 1 & $12(30)$ & $17(57)$ & $20(69)$ & ns & \\
\hline 2 & II (28) & $13(43)$ & $9(3 \mathrm{I})$ & ns & \\
\hline 3 & $17(43)$ & 0 & 0 & $<0,0$ I & $\begin{array}{l}\text { Dependent/independentand dependent/ } \\
\text { semi-dependent }\end{array}$ \\
\hline \multicolumn{6}{|l|}{ Number of diseases, $\mathrm{N}(\%)$} \\
\hline 0 & $4(10)$ & $5(17)$ & $3(10)$ & ns & \\
\hline I & $12(30)$ & $6(20)$ & $8(28)$ & ns & \\
\hline 2 & $9(23)$ & $6(20)$ & $5(17)$ & ns & \\
\hline 3 & $8(20)$ & $8(27)$ & $7(24)$ & ns & \\
\hline 4 & $3(8)$ & $2(7)$ & $2(7)$ & ns & \\
\hline 5 & $4(10)$ & $3(10)$ & $3(10)$ & ns & \\
\hline 6 & 0 & 0 & I (3) & ns & \\
\hline \multicolumn{6}{|l|}{ Disease type, $N(\%)$} \\
\hline COPD & $3(8)$ & $2(7)$ & $5(17)$ & ns & \\
\hline Heart disease & $14(35)$ & $2(7)$ & $3(10)$ & $<0,01$ & $\begin{array}{l}\text { Dependent/independent and depen- } \\
\text { dent/semi-dependent }\end{array}$ \\
\hline Hypertension & $25(63)$ & $18(60)$ & $17(59)$ & ns & \\
\hline Stroke & $8(20)$ & $4(13)$ & I (3) & 0,06 & Dependent/independent only \\
\hline Kidney/Gall stones & $3(8)$ & $3(10)$ & $4(14)$ & ns & \\
\hline Kidney disorder & I (3) & 0 & I (3) & ns & \\
\hline Diabetes & $6(15)$ & $9(30)$ & $5(17)$ & ns & \\
\hline Joint disorders & $20(50)$ & $16(53)$ & $17(59)$ & ns & \\
\hline Epilepsy & I (3) & I (3) & I (3) & ns & \\
\hline Cancer & $3(8)$ & $4(13)$ & $5(17)$ & ns & \\
\hline Psychological disorder & $2(5)$ & $6(20)$ & $9(31)$ & ns & \\
\hline
\end{tabular}

Notes: ns: not significant (significance level $=<0.05$ ).

\section{Discussion}

Valuing well-being health states relates to the fact that factors like age, disability and dependency affects how elderly value health states. ${ }^{5,30}$

This study investigated Dutch elderly health state valuations, using both a utility-based and capabilitybased questionnaire and reported on the implicit nature of how the oldest old subgroups conceptualize HRQoL health states when compared to well-being health states.

The first important result from the EQ-5D+C questionnaire indicates that all three subgroups ranked the bottom five-health states, 133113, 212321, 333211, 323331 and 333333 , below the average scores of the subgroups. This is an important finding, since this indicates that, subjectively, 
Table 2 EQ-5D+C valuations of the oldest old subgroups

\begin{tabular}{|l|l|l|l|}
\hline $\begin{array}{l}\text { Health } \\
\text { states }\end{array}$ & Dependent & $\begin{array}{l}\text { Semi- } \\
\text { dependent }\end{array}$ & Independent \\
\hline$I I I I I I$ & 1.00 & 1.00 & 1.00 \\
$|I| 2 \mid I 2$ & 0.83 & 0.75 & 0.77 \\
$2|2| I I \mid$ & 0.82 & 0.76 & 0.77 \\
$|I| 22 \mid$ & 0.76 & 0.74 & 0.71 \\
$2|2| 2 \mid$ & 0.77 & 0.70 & 0.70 \\
$|33| \mid 3$ & $\mathbf{0 . 5 4}$ & $\mathbf{0 . 4 7}$ & $\mathbf{0 . 4 9}$ \\
$2|232|$ & $\mathbf{0 . 4 9}$ & $\mathbf{0 . 4 8}$ & $\mathbf{0 . 5 2}$ \\
$3332 \mid I$ & $\mathbf{0 . 4 4}$ & $\mathbf{0 . 4 3}$ & $\mathbf{0 . 4 I}$ \\
$32333 \mid$ & $\mathbf{0 . 3 7}$ & $\mathbf{0 . 3 7}$ & $\mathbf{0 . 3 4}$ \\
333333 & $\mathbf{0 . 2 4}$ & $\mathbf{0 . 2 0}$ & $\mathbf{0 . 2 0}$ \\
Average across & 0.63 & 0.59 & 0.59 \\
health states & & & \\
\hline
\end{tabular}

Note: The bold values indicate below subgroup average values.

Table 3 CAF valuations of oldest old subgroups

\begin{tabular}{|l|l|l|l|}
\hline $\begin{array}{l}\text { Health } \\
\text { states }\end{array}$ & Dependent & $\begin{array}{l}\text { Semi- } \\
\text { dependent }\end{array}$ & Independent \\
\hline 11111 & 1.00 & 1.00 & 1.00 \\
11122 & 0.92 & 0.95 & 0.94 \\
111245 & $\mathbf{0 . 6 2}$ & $\mathbf{0 . 6 6}$ & $\mathbf{0 . 6 0}$ \\
11312 & 0.87 & 0.89 & 0.87 \\
12335 & $\mathbf{0 . 7 4}$ & $\mathbf{0 . 7 3}$ & $\mathbf{0 . 6 9}$ \\
21114 & 0.84 & 0.82 & 0.80 \\
33333 & $\mathbf{0 . 7 3}$ & 0.76 & 0.75 \\
33544 & $\mathbf{0 . 5 8}$ & $\mathbf{0 . 5 3}$ & $\mathbf{0 . 4 9}$ \\
44433 & $\mathbf{0 . 6 3}$ & $\mathbf{0 . 5 6}$ & $\mathbf{0 . 5 0}$ \\
55555 & $\mathbf{0 . 4 2}$ & $\mathbf{0 . 4 1}$ & $\mathbf{0 . 3 3}$ \\
Average across & 0.74 & 0.73 & 0.70 \\
health states & & & \\
\hline
\end{tabular}

Note: The bold values indicate below subgroup average values.

the participants view the lowest five-health states as undesirable or unacceptable. Implicitly this suggests that the oldest old might deem the health states above the subgroup average as acceptable and part of the process of aging. Conceptually, this has implications for current practice guidelines when defining disability within groups, individuals or populations. If individuals, within a certain group, can agree that specific deficits in health are acceptable, then treatment guidelines for those health states should be adjusted accordingly. Suggesting that the concept of disability within a group like the oldest old should be re-examined and redefined to include the views of the oldest old. ${ }^{3}$

The dependent elderly valued the majority of the health states the highest of the three groups, despite the reality of decline and higher prevalence of stroke and heart disease in this subgroup of elderly. ${ }^{31}$ This result reinforces the idea that being dependent does not mean that the elderly are experiencing negative sentiments regarding future health and quality of life. The dependent elderly still place a higher valuation on worse off health states, when compared to the other two groups. A possible explanation can be the fact that the dependent elderly has adapted to the "new" level of disability and view worse off health states better than the semi-dependent and independent groups. ${ }^{32}$ This allows the dependent elderly to have an optimistic view on future health capabilities.

As for the CAF valuations, all the subgroups ranked health states $11245,12335,33544,44433$ and 55555 equal to or below the subgroup average. As with the EQ-5D+C health states, this is noteworthy, since this suggests that subjectively, the participants view health states 11245 , $12335,33544,44433$ and 55555 as undesirable, while the remaining health states might be viewed as acceptable. If certain health states are deemed acceptable, while some are deemed unacceptable, this should result in the adjustment of disability threshold values and treatment guidelines. $^{33}$

The dependent elderly valued the health states the highest of the three groups. Here again, it is clear that being dependent does not mean that the elderly are experiencing negative sentiments regarding their future functionings and well-being. Adapting to disability allows the dependent elderly to be optimistic about worse off nonhealth related health states. ${ }^{34}$

Second, the subgroup average values across the health states of the CAF health states are higher than the health states of the EQ-5D+C questionnaire. In addition, comparing the below average ranked health states of the EQ-5D+C and CAF, shows that the oldest old, do view deficits in health-related health states as more important than deficits in well-being health states. This concept is supported by a previous study indicating that when people value EQ-5D health states, they already consider the effects the health deficits will have on nonhealth aspects of their lives. ${ }^{6}$ It would appear that EQ$5 \mathrm{D}+\mathrm{C}$ health states refer to physical, mental and cognitive decline, which the oldest old individuals may recognize as part of the aging process, ${ }^{32}$ but conceptually the oldest old also realize the effects these health deficits will have on well-being. ${ }^{35}$ This construct, the oldest old do view deficits in $\mathrm{EQ}-5 \mathrm{D}+\mathrm{C}$ health states as more important than deficits in CAF health states, might be 
of importance when achieving acceptable well-being is important to the elderly. The pathway to achieve the social support of friends and family and still have control over daily and future decisions, ${ }^{36}$ might be to preserve health-related domains like mobility, cognition and to reduce pain experience and depression. We consider the results obtained very relevant yet some limitations of the study should be mentioned.

The limitations of the study are as follows: First, the CAF questionnaire is a conceptual questionnaire and not yet widely applied and utilized in subsequent studies. The pilot studies performed, however, confirmed the feasibility of the CAF questionnaire for use in our study. Second, not all participants adhered to the definition of oldest old, although the average age of the three groups were all 80 years and above.

Finally, since this study was performed in the Northern part of the Netherlands and with a relatively small number of respondents, future studies must include more respondents and include more Dutch regions to further support the conclusions made by this study. Amid these limitations, the strength of this study is significant since important findings were substantiated, and new associations were found. Another strong point may be the fact that the results are in line with previous research and evidence and that the associations investigated are quite robust.

The results from this study reinforce the results from previous studies indicating that a capability-based instrument, like the CAF, not only provides complementary information to the $\mathrm{EQ}-5 \mathrm{D}+\mathrm{C}$, but elderly subgroups, also value similar hypothetical health-related and well-being health states as unacceptable.

\section{Conclusions}

Health state valuations performed by the oldest old indicate that conceptually, respondents view below average health-related and well-being health states as undesirable. The results also indicate that the oldest old, do view deficits in health-related health states, as more important than deficits in well-being health states. Possibly, due to the fact that preservation of function is deemed important by the oldest old. This suggests that focused interventions to improve or avoid below average health-related outcomes, like limited mobility, pain and cognitive impairment might be the most cost-effective way to increase oldest old well-being outcomes.

\section{Acknowledgments}

The University of Groningen as part of a $\mathrm{PhD}$ project funded this study. The funder had no role in the design of the study, data collection, analysis, and interpretation of data nor in writing the manuscript.

\section{Disclosure}

The authors report no conflicts of interest in this work.

\section{References}

1. Norman R, Cronin P, Viney R, King M, Street D, Ratcliffe J. International comparisons in valuing EQ-5D health states: a review and analysis. Value Health. 2009;12(8):1194-1200. doi:10.1111/ j.1524-4733.2009.00581.x

2. Stamuli E. Health outcomes in economic evaluation: who should value health? Br Med Bull. 2011;97:197-210. doi:10.1093/bmb/ ldr001

3. Gopinath M. Thinking about later life: insights from the capability approach. Ageing Int. 2018;43(2):254-264. doi:10.1007/s12126-0189323-0

4. Essink-Bot ML, Stuifbergen MC, Meerding WJ, Looman CW, Bonsel GJ. Individual differences in the use of the response scale determine valuations of hypothetical health states: an empirical study. BMC Health Serv Res. 2007;7:62. doi:10.1186/1472-6963-7-62

5. Ebrahim S, Brittis S, Wu A. The valuation of states of ill-health: the impact of age and disability. Age Ageing. 1991;20(1):37-40. doi:10.1093/ageing/20.1.37

6. Karimi M, Brazier J, Paisley S. How do individuals value health states? A qualitative investigation. Soc Sci Med. 2017;172:80-88. doi:10.1016/j.socscimed.2016.11.027

7. van BS, Perenboom R. The fountain of age: a remarkable 3D shape that portrays health and functional differences among the European elderly. Int J Environ Res Public Health. 2014;11(4):4078-4090. doi:10.3390/ijerph110909256

8. Karppinen H, Laakkonen ML, Strandberg TE, Huohvanainen EA, Pitkala KH. Do you want to live to be 100? Answers from older people. Age Ageing. 2016;45:543-549. doi:10.1093/ageing/afw059

9. Chatterji S, Byles J, Cutler D, Seeman T, Verdes E. Health, functioning, and disability in older adults-present status and future implications. Lancet. 2015;385(9967):563-575. doi:10.1016/S0140-6736(14)61462-8

10. Banerjee S. Multimorbidity-older adults need health care that can count past one. Lancet. 2015;385(9968):587-589. doi:10.1016/ S0140-6736(14)61596-8

11. Lamers LM, McDonnell J, Stalmeier PF, Krabbe PF, Busschbach JJ. The Dutch tariff: results and arguments for an effective design for national EQ-5D valuation studies. Health Econ. 2006;15 (10):1121-1132. doi:10.1002/(ISSN)1099-1050

12. Mann R, Brazier J, Tsuchiya A. A comparison of patient and general population weightings of EQ-5D dimensions. Health Econ. 2009;18 (3):363-372. doi: $10.1002 /$ hec. 1525

13. Davis JC, Liu-Ambrose T, Richardson CG, Bryan S. A comparison of the ICECAP-O with EQ-5D in a falls prevention clinical setting: are they complements or substitutes? Qual Life Res. 2012;22:969-977.

14. van Leeuwen KM, Jansen AP, Muntinga ME, et al. Exploration of the content validity and feasibility of the EQ-5D-3L, ICECAP-O and ASCOT in older adults. BMC Health Serv Res. 2015;15:201. doi:10.1186/s12913-015-0718-2

15. Anand P, Hunter G, Smith R. Capabilities and well-being: evidence based on the Sen-Nussbaum approach to welfare. Soc Indec Res. 2005;74:9. doi:10.1007/s11205-005-6518-z 
16. Krishnakumar J. Going beyond functionings to capabilities: an econometric model to explain and estimate capabilities. J Hum Dev. 2007;8(1):39-63. doi:10.1080/14649880601101408

17. Anand P. Capabilities and Health. J Med Ethics. 2005;31(5):299-303. doi:10.1136/jme.2004.008706

18. Venkatapuram S. Health, vital goals, and central human capabilities. Bioethics. 2012;27:271-279.

19. Kirsch J, McGuire A. Establishing health state valuations for disease specific states: an example from heart disease. Health Econ. 2000;9 (2):149-158. doi:10.1002/(ISSN)1099-1050

20. Bos EH, Snippe E, de JP, Jeronimus BF. Preserving subjective wellbeing in the face of psychopathology: buffering effects of personal strengths and resources. PLoS One. 2016;11(3):e0150867. doi:10.1371/journal.pone.0150867

21. Arai H, Ouchi Y, Yokode M, et al. Toward the realization of a better aged society: messages from gerontology and geriatrics. Geriatr Gerontol Int. 2012;12(1):16-22. doi:10.1111/j.14470594.2011.00776.x

22. Hoeymans N, van LH, Westert GP. The health status of the Dutch population as assessed by the EQ-6D. Qual Life Res. 2005;14 (3):655-663. doi:10.1007/s11136-004-1214-z

23. Krabbe PF, Stouthard ME, Essink-Bot ML, Bonsel GJ. The effect of adding a cognitive dimension to the EuroQol multiattribute health-status classification system. J Clin Epidemiol. 1999;52 (4):293-301.

24. Coast J, Flynn TN, Natarajan L, et al. Valuing the ICECAP capability index for older people. Soc Sci Med. 2008;67(5):874-882. doi:10.1016/j.socscimed.2008.05.015

25. Grewal I, Lewis J, Flynn T, Brown J, Bond J, Coast J. Developing attributes for a generic quality of life measure for older people: preferences or capabilities? Soc Sci Med. 2006;62(8):1891-1901. doi:10.1016/j.socscimed.2005.08.023

26. Coast J, Peters TJ, Natarajan L, Sproston K, Flynn T. An assessment of the construct validity of the descriptive system for the ICECAP capability measure for older people. Qual Life Res. 2008;17 (7):967-976. doi:10.1007/s11136-008-9372-z
27. Botes R, Vermeulen KM, Ranchor AV, Buskens E. Functional health state description and valuation by people aged 65 and over: a pilot study. BMC Geriatr. 2018;18(1):11. doi:10.1186/s12877-018-0711-9

28. Craig BM, Busschbach JJ, Salomon JA. Modeling ranking, time trade-off, and visual analog scale values for EQ-5D health states: a review and comparison of methods. Med Care. 2009;47 (6):634-641. doi:10.1097/MLR.0b013e31819432ba

29. Brazier J, Ratcliffe J, Salomon J, Tsuchiya A. Measuring and Valuing Health Benefits for Economic Evaluation. United States: Oxford University Press; 2007.

30. Dolan P. Effect of age on health state valuations. J Health Serv Res Policy. 2000;5(1):17-21. doi:10.1177/135581960000500106

31. Tabali M, Ostermann T, Jeschke E, Dassen T, Heinze C. Does the care dependency of nursing home residents influence their health-related quality of life?-A cross-sectional study. Health Qual Life Outcomes. 2013;11:41. doi:10.1186/1477-7525-11-83

32. Fauth EB, Gerstorf D, Ram N, Malmberg B. Changes in depressive symptoms in the context of disablement processes: role of demographic characteristics, cognitive function, health, and social support. J Gerontol B Psychol Sci Soc Sci. 2012;67(2):167-177. doi:10.1093/geronb/gbr078

33. Jopp D, Rott C, Oswald F. Valuation of life in old and very old age: the role of sociodemographic, social, and health resources for positive adaptation. Gerontologist. 2008;48(5):646-658. doi:10.1093/geront $/ 48.5 .646$

34. Romo RD, Wallhagen MI, Yourman L, et al. Perceptions of successful aging among diverse elders with late-life disability. Gerontologist. 2013;53(6):939-949. doi:10.1093/geront/gns 160

35. Benning TM, Alayli-Goebbels AF, Aarts MJ, et al. Exploring outcomes to consider in economic evaluations of health promotion programs: what broader non-health outcomes matter most?BMC Health Serv Res. 2015;15:266. doi:10.1186/s12913-015-0718-2

36. Hofman CS, Makai P, Boter H, et al. The influence of age on health valuations: the older olds prefer functional independence while the younger olds prefer less morbidity. Clin Interv Aging. 2015;10:1131-1139. doi:10.2147/CIA.S78698
Patient Preference and Adherence

\section{Publish your work in this journal}

Patient Preference and Adherence is an international, peer-reviewed, open access journal that focusing on the growing importance of patient preference and adherence throughout the therapeutic continuum. Patient satisfaction, acceptability, quality of life, compliance, persistence and their role in developing new therapeutic modalities and compounds to optimize clinical outcomes for existing disease states are major areas of interest for the journal. This journal has been accepted for indexing on PubMed Central. The manuscrip management system is completely online and includes a very quick and fair peer-review system, which is all easy to use. Visit http:// www.dovepress.com/testimonials.php to read real quotes from published authors. 